\title{
Psychosocial Adaptation in Relatives of Critically Injured Patients Admitted to an Intensive Care Unit
}

\author{
Agustín Martín Rodríguez \\ $\mathrm{M}^{\mathrm{a}}$ Ángeles Pérez San Gregorio \\ University of Seville
}

The aim of this study is to analyze how the length of time a patient spends in an Intensive Care Unit (ICU) affects close relatives, with regard to specific clinical variables of personality, family relationships and fear of death. The study group consisted of 57 relatives of seriously ill patients admitted to the ICU of "Virgen del Rocío" Rehabilitation and Trauma Hospital (Seville, Spain). The instruments applied were: a psychosocial questionnaire, clinical analysis questionnaire, family environment scale and fear of death scale. The relatives of patients admitted to ICU obtained higher scores in hypochondria, suicidal depression, agitation, anxious depression, guilt-resentment, paranoia, psychasthenia, psychological maladjustment and self-expression, and less in fear of their own death, as when compared to interviews with the same relatives 4 years later. The length of time a patient spent in the ICU influenced relatives in some clinical variables of personality, family relationships and fear of death.

Keywords: intensive care, personality, family environment, fear of death,

Hemos analizado la influencia del tiempo transcurrido desde el ingreso del paciente en la $\mathrm{UCI}$ en sus familiares mas allegados, sobre determinadas variables clínicas de personalidad, las relaciones familiares y el temor experimentado ante la muerte. La muestra estaba formada por 57 familiares de pacientes traumatizados graves ingresados en la UCI de Traumatología. Hemos empleado una encuesta psicosocial y los siguientes instrumentos: Cuestionario de Análisis Clínico, Escala de Clima Social en la Familia y Escala de Temor a la Muerte. Los familiares de pacientes ingresados en la $\mathrm{UCl}$, comparados con los mismos familiares cuatro años después del ingreso, obtienen puntuaciones más elevadas en hipocondria, depresión suicida, agitación, depresión ansiosa, culpabilidad-resentimiento, paranoia, psicastenia, desajuste psicológico y expresividad, y menor en el temor al proceso de morir propio. El tiempo transcurrido desde el ingreso del paciente en la $\mathrm{UCl}$ ejerce una influencia sobre sus familiares en algunas variables clínicas de personalidad, las relaciones familiares y el temor experimentado ante la muerte.

Palabras claves: cuidados críticos, personalidad, clima familiar, temor a la muerte

We are grateful to the staff at "Virgen del Rocío" Hospital (Seville, Spain) for their sustained support.

Correspondence concerning this article should be addressed to Agustín Martín Rodríguez, University of Seville, Dept. of Psychology, C/ Camilo José Cela, s/n, Seville, 41018, Spain. E-mail: amartinr@us.es.

Translation: Jean L. Feuerstein 
Intensive Care Units (ICU) are probably the most complex and stressful units throughout any hospital. The growing development of these units has served to highlight a series of psychological signs, sometimes serious and important, in patients as well as their relatives (Bennun, 1999; Gómez, López, \& Cirera, 1997; Pérez, 2001).

Regarding patients, the incidence of psychological disorders is estimated between 14 and $72 \%$, of which, the most common are anxiety, depression and delirium. Factors that contribute to the onset of psychological problems in ICU patients are, among others, adaptation to the new situation, previous personality, physiological alterations due to the illness, medication, the effect the ICU environment has on sleep and lack of sensory stimulation, and finally, the type of interaction between the patient and hospital/medical staff (Dörr-Zegers, 1988; Gómez et al., 1997). Also, patients have to abandon, at least temporarily, the roles they previously held (family, work, etc.) and adopt a passive and dependent role towards hospital staff and the machines and equipment surrounding them (Frías, 1994). As a consequence, identity and social integration can be difficult to achieve and maintain when these individuals are not in a familiar environment, are without their normal attire, and when conversations held are mostly about them, but do not include them (Bennun, 1999).

And so, when a patient is hospitalized in ICU, a series of prophylactic measures must be taken to prevent the appearance of psychological and/or psychiatric disorders. Gómez et al., consider the recommended measures to be the following: 1) provide a comfortable atmosphere with proper temperature control, without monotonous noise and with natural light so the patient perceives diurnal changes; 2) maintain equipment/monitors out of the patients' view and prevent possible false alarms that can frighten him/her; 3) avoid loss of temporal orientation by allowing the patient to have his/her watch, a calendar and personal objects nearby; 4)make sure the patient feels that hospital staff is watching over them (s/he can hear or see them); 5) protect them from critical situations or deaths in their proximity; 6) avoid making medical comments in front of the patient that can be misunderstood; 7) allow relatives to visit and have contact with the patient, only if it does not add to a feeling of anxiety; 8) avoid loud voices and laughter by hospital staff which can create a feeling of abandonment in the patient; 9) give the patient an adequate explanation regarding his/her condition; 10) educate the patient regarding his/her treatment and comment on the positive aspects of the therapeutic plan; 11) explore fears and misunderstanding regarding their condition; 12) maintain open and direct communication which allows, but does not force, feelings to be expressed; 13) give real hope, but not false hope; 14) maintain calm during visits and 15) inform and prepare the patient before moving him/her to another floor or area of the hospital.

Nevertheless, when the patient is released from ICU, and later from the hospital, many times there are physical and psychological consequences that occur which generate stress, as it might be difficult to return to their previous state of health (Anguera, 1978).

Not only patients, but also close relatives of those admitted to ICU can develop emotional disorders. Relatives experience a wide variety of behaviors and emotions such as fear, shock reaction, scepticism, hopelessness, guilt, anxiety, confusion, etc. (Jay, 1977; Rothstein, 1980). Most of the time, the reactions described by relatives of patients in ICU do not end up to be mental disorders. They have, as all reactions do, a rather concrete localization in a determined time, after which the symptoms begin to diminish (Pérez, Murillo, Dominguez, \& Nuñez, 1992). However, there are multiple factors that can cause these disorders. For example, the patients' condition might be uncertain, the procedures and treatments are generally painful and invasive, and the atmosphere is stressful. Relatives have to interact with people who are unknown to them, the technology and therapeutic processes can be frightening, and the physical appearance of their relatives or other patients is usually altered (Brome, 1985; Pérez \& Lozano, 1994).

Nonetheless, the evolution of the aforementioned reactions into more or less serious psychological problems will depend on other added factors such as the physical and mental consequences suffered by the patient, his/her quality of life after being released by the hospital, or even the patients' death, etc. As a result, if the circumstances get complicated, the relatives of these patients can develop diverse clinical symptoms that can be compared to mental disorders such as adaptive disorders, post-traumatic stress disorders, complicated bereavement, etc. (American Psychiatric Association, Diagnostic and Statistical Manual of Mental Disorders (4 ${ }^{\text {th }}$ ed.),1994).

Many patients survive after being admitted to an ICU, however the mortality rate continues to be an insufficient gauge for evaluating it's efficiency. This is why a number of investigations recommend evaluating the quality of life of the patient after being released from the hospital, as well as psychological aspects, with the aim of detecting the needs and problems of ICU survivors and developing intervention strategies (Brooks, Kerridge, Hillman, Bauman, \& Daffurn, 1997; Capuzzo, Bianconi, Contu, Pavoni, \& Gritti, 1996; Zarén \& Hedstrand, 1987).

Regarding relatives of patients who have been in ICU, sometimes they have to assume care of the patient after their release. At times, these patients suffer from physical and psychological consequences of their condition (paraplegics, quadriplegics, traumatic amputations, cognitive deficits, etc.). For this reason, the hardships of the relatives are considered when the deterioration of the patients' quality of life is more or less permanent, the illness is or becomes chronic, or because of the disabilities resulting from the illness and/or treatment received in ICU (Affleck, Tennen, \& Rowe, 1990; Anguera, 1978; Flórez, 2001). Recent studies regarding the 
effect of long term stress on relatives caring for patients with a poor quality of life have provided empirical evidence of the negative consequences experienced by them. The stress experienced by relatives increases the risk that they demonstrate unhealthy behaviors such as inadequate rest, lack of exercise and a poor diet. Relatives run the risk of not attending to their own needs (Fuller-Jonap \& Haley, 1995) which has been demonstrated in studies that show an increase the use of psychotropic drugs and poor selfassessment (Schulz, O'Brien, Bookwala, \& Fleissner, 1995). These relatives are also at risk of suffering from cardiovascular problems according to investigations that show an increase in blood pressure in women caregivers (King, Oka, \&Young, 1994). Likewise, the results of some studies regarding relatives who care for patients, and who find it difficult to express anger or their feelings, demonstrate physiological changes in these relatives (Vitaliano, Russo, \& Niaura, 1995).

Given the relevance of this subject, the main objective of the present study is to analyze how the passing of time influences relatives of patients admitted to ICU regarding the three following variables: a) Personality variables (hypochondria, suicidal depression, agitation, anxious depression, low-energy depression, guilty-resentment, apathywithdrawal, paranoia, psychopathic deviation, schizophrenia, psychasthenia and psychological maladjustment); b) family relationships (cohesion, expressivity and conflict) and c) fear of death (fear of one's own death, someone else's death, fear of one's own dying and the fear of someone else's dying).

\section{Method}

\section{Participants}

The participants in the present study were 57 relatives of critically injured patients admitted to the ICU at "Virgen del Rocío" Rehabilitation and Trauma Hospital (Seville, Spain). One relative per patient participated. The average age of the sample was 40.47 years. With regard to sex, males barely predominated at $52.6 \%$. Regarding the relationship between the relative and patients, a great majority, $49.1 \%$, were fathers and/or mothers, followed by husband/wife (19.3\%), brother/sister (17.5\%), son/daughter $(8.8 \%)$, and others $(5.3 \%)$. Concerning education levels, we saw that more than half the subjects $(54.4 \%)$ had completed primary studies. As for the patients, the average age was 26.63 years, and the large majority were men $(78.9 \%)$. Education levels of the patients were distributed into two fundamental categories, $50.9 \%$ with primary studies and $33.3 \%$ with primary or secondary studies. The most common diagnosis among these critically injured patients in ICU was head and brain trauma $(47.4 \%)$ followed by head and brain trauma as well as polytraumatized (26.3\%), polytraumatized patients (22.8\%), and traumatic quadriplegics (3.5\%). The average amount of time these patients spent in ICU was 15.49 days.

\section{Instruments}

The following is a description of the psychological instruments used in this study: 1) Psychosocial survey- which was developed by the authors of the current research and centered on sociodemographic data as well as all medical aspects (patient diagnosis, time spent in ICU, etc.).

2) Clinical Analysis Questionnaire (Krugg, 1987)- this is a test with a factorial design used to measure clinical characteristics in normal subjects, or, in other words, clinical psychopathological aspects of a normal personality. It consists of 144 elements, each with three alternative responses which can receive 2, 1 or 0 points. These elements are grouped into twelve subscales and the maximum score for each is 24 points. These subscales define twelve fundamental dimensions: hypochondria, suicidal depression, agitation, anxious depression, low-energy depression, guilt-resentment, apathywithdrawal, paranoia, psychopathic deviation, schizophrenia, psychasthenia and psychological maladjustment. The reliability index of the diverse scales in the Spanish experimental samples were calculated using the Kurder-Richardson KR20 formula and were as follows: hypochondria (0.49), suicidal depression (0.50), agitation (0.16), anxious depression (0.54), low-energy depression (0.64), guilt-resentment (0.72), apathywithdrawal (0.45), paranoia (0.60), psychopathic deviation (0.42), schizophrenia $(0.51)$, psychasthenia $(0.44)$ and psychological maladjustment (0.67).

3) Family Environment Scale (Moos, Moos \& Trickett, 1989)- this scale evaluates and describes the interpersonal relationships between members of the family, the most important aspects of their development and their basic structure. It includes 90 elements that are grouped into 10 subscales which define three fundamental dimensions: relationships, development and stability. In the present study, only the relationships dimension was used. This dimension is comprised of 27 elements, each having 2 alternative responses (true or false) and is marked dichotomously (1 or 0$)$. These elements are grouped into three scales and the maximum score in any scale is nine points. These three scales define three fundamental dimensions: cohesion, expressivity and conflict. To calculate the reliability for the scales, three procedures were used: 1) Test-retest (rtt; calculating the correlation between the first and second application with a 2 month time interval; 2) the Internal Consistency Index (rxx; Kuder-Richardson's KR20 and KR21 formula) and the Homogeneity Index (rxe; an average of the relationships of all the elements within the scale). Specifically, the reliability indexes obtained in the three scales used were: cohesion $(\mathrm{rtt}=0.86, \mathrm{rxx}=0.78, \mathrm{rxe}=$ 0.44 ), expressivity $(\mathrm{rtt}=0.73, \mathrm{rxx}=0.69$, $\mathrm{rxe}=0.34)$ and conflict ( $\mathrm{rtt}=0.85, \mathrm{rxx}=0.75$, $\mathrm{rxe}=0.43$ ). 
4) Fear of Death Scale (Urraca, 1981)- evaluates fear experienced regarding death, which helps us to understand the state of anxiety caused by suffering from a terminal illness, the terminal degenerative process and/or the affect death might have on relatives. It consists of 36 elements, each with 6 alternative responses: 1(strongly disagree), 2 (somewhat disagree), 3 (slightly disagree), 4 (slightly agree), 5 (somewhat agree) and 6 (strongly agree). Scoring of each element depends on the alternative chosen and the nature of the sentence (written positively or negatively). It is made of four subscales which evaluate four different aspects of the fear of death: fear of one's own death, fear of someone else's death, fear of one's own dying, and fear of someone else's dying. The alpha reliability coefficient was quite high (0.70519), indicating that the items contained in this scale adequately represent the items referring to fear of death.

\section{Procedure}

Data collection for this study took place at two different times. The first was when the critically injured patient was admitted to the ICU, forming the ICU subject group and consisting of 57 relatives of these patients. They were selected among all the patients admitted during the period of a year, to the ICU of "Virgen del Rocío" Rehabilitation and Trauma Hospital (Seville, Spain). In the study, we concentrated on the relatives of critically injured patients (head and brain trauma, polytraumatized patients and traumatic quadriplegics) whose admission to the ICU was sudden and a result of an unexpected accident (traffic, high fall, hit by car, etc.)

The second period of data collection, from the same 57 relatives, took place 4 years after the patient had been admitted to ICU. A letter was sent to the relative of each patient thanking them for their voluntary collaboration in the study during the time that the patient was in ICU, and requested their collaboration, and that of the patient, for a second interview to complete the study.

All of the relatives of the ICU patients were subjected to the same administrative conditions, regarding individual test application by a psychologist with identical instructions for everyone. Subjects were first given a brief explanation of the objective of the study, what the interview would consisted of, and were told that answering test questions well was of upmost importance. In each case, the psychologist read the questions aloud and made a note of the subjects' answers without changing, amplifying or interpreting the questions or recommending a determined response.

Firstly, the investigator obtained the data concerning the psychosocial survey. Secondly, and always following the same order, he/she obtained the data for the following psychological instruments: Clinical Analysis Questionnaire (Krugg, 1987), Family Environment Scale (Moos, et al.,
1989) and the Fear of Death Scale (Urraca, 1981). The influences that this particular order of application might produce are constant and therefore are not considered essential.

Sociodemographic data, as well as data concerning specific aspects of the ICU when the patients were admitted, were taken from information given by their relatives and/or their medical history.

The criteria in selecting the relatives of patients (at the time the patient was admitted as well as four years later) were the following: 1) that the patient did not die during his/her stay in the ICU (since death would involve an additional, highly stressful factor), 2) that the patient was over 14 years of age at the time of selection (in very few cases, the patients were younger than 14, and psychological repercussions are different when treating an adult or child), 3) that they reside in Andalucía (as to reduce economic cost and time involving the interviews), 4) that the relative did not have a history of alcohol or drug abuse or depressive disorders, since these disorders, in themselves, have psychosocial repercussions that affect the patient and his/her relatives, and 5) that they had all psychometric measurements and or sociodemographic data collected during the time the patient was admitted to the ICU (essential to perform the follow-up study).

\section{Results}

\section{Comparison of the Clinical Variables of Personality}

The Student-Fisher $\mathrm{t}$ test for related samples was applied to the variables measured by the Clinical Analysis Questionnaire (hypochondria, suicidal depression, agitation, anxious depression, low-energy depression, guilt-resentment, apathy-withdrawal, paranoia, psychopathic deviation, schizophrenia, psychasthenia and psychological maladjustment). Results are shown in Tables 1 and 2.

As is shown in the analysis of these tables, significant differences were found in the following variables: hypochondria, suicidal depression, agitation, anxious depression, guilt-resentment, paranoia, psychasthenia and psychological maladjustment. We can see, in Table 1, that in all variables, the relatives scored higher when the patient was in ICU as compared to 4 years afterwards.

\section{Comparison of Family Relationship Variables}

As in the aforementioned section, the Student-Fisher $\mathrm{t}$ test was applied to samples related to the cohesion, expressivity and conflict variables. Expressivity was the only variable with significant results $(p \leq 0.005)$. Relatives scored higher when the patient was in ICU as compared to 4 years afterwards (see Tables 3 and 4). 
Table 1

Summary of statistics for clinical variables of personality in the relatives group: during ICU stay and post-ICU

\begin{tabular}{lcccc}
\hline \multirow{2}{*}{ Subscales } & \multicolumn{2}{c}{ Relatives during ICU stay } & \multicolumn{2}{c}{ Relatives post-ICU } \\
\cline { 2 - 5 } & Average (+) & SD & Average (+) \\
\hline Hypochondria & 5.58 & 4.29 & 4.07 & 3.31 \\
Suicidal Depression & 4.91 & 4.05 & 3.44 & 3.68 \\
Agitation & 10.16 & 38. & 7.04 & 3.81 \\
Anxious Depression & 8.58 & 3.98 & 7.84 & 2.95 \\
Low-energy Depression & 7.02 & 5.18 & 7.12 & 3.72 \\
Guilt-resentment & 9.26 & 5.07 & 5.96 & 3.81 \\
Apathy-withdrawal & 6.42 & 3.37 & 13.46 & 3.24 \\
Paranoia & 9.6 & 3.92 & 4 & 3.42 \\
Psychopathic Deviation & 12.63 & 3.23 & 9.98 & 2.84 \\
Schizophrenia & 4.77 & 3.3 & 3.7 & 3.07 \\
Psychasthenia & 11.82 & 3.79 & 3.41 & 3.49 \\
Psychological Maladjustment & 5.16 & & 3 \\
\hline
\end{tabular}

Note. (+): averages taken from the actual scores.

Table 2

Student-Fisher $t$ for the clinical variables of personality in the relatives group: during ICU stay and post-ICU

\begin{tabular}{lccc}
\hline Subscales & $T$ & f.d & Sign. P. \\
\hline Hypochondria & 3.03 & 56 & $0.004 * *$ \\
Suicidal Depression & 2.86 & 56 & $0.006^{* *}$ \\
Agitation & 3.74 & 56 & $0.001^{* *}$ \\
Anxious Depression & 3.32 & 56 & $0.002^{* *}$ \\
Low-energy Depression & -1.34 & 56 & 0.184 \\
Guilt-resentment & 3.52 & 56 & $0.001^{* *}$ \\
Apathy-withdrawal & 0.83 & 56 & 0.406 \\
Paranoia & 3.26 & 56 & $0.002^{* *}$ \\
Psychopathic Deviation & -1.67 & 56 & 0.099 \\
Schizophrenia & 1.64 & 56 & 0.106 \\
Psychasthenia & 3.16 & 56 & $0.002^{* *}$ \\
Psychological Maladjustment & 2.59 & 56 & $0.012^{* *}$ \\
\hline
\end{tabular}

Note. $* * \mathrm{p} \leq 0.01$

Table 3

Summary of statistics for the family relationship variables in the relatives group: during ICU stay and post-ICU

\begin{tabular}{lcccc}
\hline \multirow{2}{*}{ Subscales } & \multicolumn{2}{c}{ Relatives during ICU stay } & \multicolumn{2}{c}{ Relatives post-ICU } \\
\cline { 2 - 5 } & Average (+) & SD & Average (+) & SD \\
\hline Cohesion & 7.7 & 1.82 & 7.63 & 1.98 \\
Expressivity & 6.33 & 1.12 & 5.89 & 1.5 \\
Conflict & 2.07 & 1.62 & 2.05 & 1.66 \\
\hline
\end{tabular}

Note. (+): averages taken from the actual scores.

Table 4

Student-Fisher t for family relationship variables in the relatives group: during ICU stay and post-ICU

\begin{tabular}{lccc}
\hline Subscales & $T$ & f.d & Sign. P. \\
\hline Cohesion & 0.24 & 56 & 0.805 \\
Expressivity & 1.99 & 56 & $0.05^{*}$ \\
Conflict & 0.06 & 56 & 0.995
\end{tabular}

Note. $* \mathrm{p} \leq 0.05$ 
Table 5

Summary of statistics for fear of death variables experienced by relatives during ICU stay and post-ICU

\begin{tabular}{lcccc}
\hline \multirow{2}{*}{ Subscales } & \multicolumn{2}{c}{ Relatives during ICU stay } & \multicolumn{2}{c}{ Relatives post-ICU } \\
\cline { 2 - 5 } & Average (+) & SD & Average (+) \\
\hline Fear of ones' own death & 34.05 & 8.48 & 34.02 & 6.53 \\
Fear of the death of others & 36.98 & 5.26 & 36.63 & 5.51 \\
Fear of ones' own death process & 26.47 & 4.41 & 28.19 & 4.71 \\
Fear of the death process of others & 37.14 & 8.56 & 35.67 & 7.4 \\
\hline
\end{tabular}

Note. (+): averages taken from the actual scores.

Table 6

Student-Fisher $t$ for variables related to the fear of death experienced by the relatives group during ICU stay and post-ICU

\begin{tabular}{lccc}
\hline Subscales & $T$ & f.d & Sign. P. \\
\hline Fear of ones' own death & 3.03 & 56 & 0.976 \\
Fear of the death of others & 0.39 & 56 & 0.698 \\
Fear of ones' own death process & -2.409 & 56 & $0.019 *$ \\
Fear of the death process of others & 1.344 & 56 & 0.185 \\
\hline
\end{tabular}

Note. $* \mathrm{p} \leq 0.05$

\section{Comparison of the Fear of Death Variables}

Again, we proceeded with the Student-Fisher t test for related samples. The only significant variable was the fear of one's own dying. Relatives scored lower when the patient was in ICU as compared to 4 years afterwards (see Tables 5 and 6).

\section{Discussion}

The results of our investigation reveal how relatives of critically injured patients admitted to an ICU find themselves, on a psychological level, as time passes. In general, at the time the patient is admitted to the ICU, his/her relatives (as compared to 4 years later): 1) worry more about health, disorders and bodily functions (hypochondria); 2) find themselves more dissatisfied with life and having selfdestructive thoughts (suicidal depression); 3) are more agitated and tireless (agitation); 4) have more disturbing dreams, tension and get agitated more easily (anxious depression); 5) on average, have more feelings of guilt (guiltresentment); 6) believe that someone is following them or mistreating them (paranoia); 7) show a greater number of obsessive behaviors, of which they claim to have little selfcontrol (psychasthenia) and 8) present with more feelings of inferiority and uselessness (psychological maladjustment). While the patient was in ICU, these relatives scored higher in two of the variables which, according to Krugg (1987), form the most important triad of depression: hypochondria, suicidal depression and low-energy depression. These results are in agreement with those found by Kendell, Slyter and
Klaus (1970) and Breslau, Staruch and Mortimer (1982), which show that relatives of patients hospitalized in ICU exhibit depressive symptoms, even when the prognosis of the patient is not negative. One possible explanation for this adverse psychological situation could lie in the psychosocial stress produced by the traumatic situation that the relatives are being exposed to. When relatives become aware that a member of their family is in critical condition, between life and death, their thoughts focus on the fact that s/he could die (Gafo et al., 1984).

At the times of both interviews, the relatives felt equally as energetic (low-energy depression), there was no reduction in interpersonal contact, they found themselves equally as comfortable with other people (apathy-withdrawal), they demonstrated the same level of inhibition regarding danger or physical pain as with social criticism (psychopathic deviation) and had the same sense of reality (schizophrenia). These results could be telling us that, even though they experience depressive feelings, relatives have to be alert and active to manage the situation at the ICU (receptive to information the hospital staff gives them, visiting hours, changes in the patients condition, etc.) and not find themselves out of touch with reality. That is, the reactions experienced by these relatives are not pathological, but small deviations stemming from a particular situation at a specific time (Pérez et al., 1992).

Regarding interpersonal relationships between family members, the results showed that relatives of critically injured patients scored higher in expressivity when the patient was in ICU as compared to 4 years later. However, we did not find differences in the two interviews regarding the cohesion and conflict variables. These findings could 
be due to the relatives' need to increase communication as a strategy to face a family members' sudden admission to ICU due to an unexpected accident. Some studies reveal the fact that improving communication and expressing painful feelings decreases anxiety and increases the relatives' ability to face the situation (Holmes-Garret, 1990).

Nevertheless, results obtained in literature regarding conflict and cohesion between relatives and patients in ICU are contradictory. On the one hand, some studies say that family conflicts rapidly get worse due to the tension caused by the patient being admitted to ICU (Benoliel, 1985). However, in an investigation carried out by Pérez et al., (1992), they revealed that these relatives felt understood, acted freely, and that the anger, aggression and conflict they had felt was absent due to the fact that hardship brings the family together and that all its members tend to disregard the conflict.

Results found in our study regarding fear of death show that there were no differences in the fear of one's own death, someone else's death or someone else's dying in relatives at the time the patient was in ICU or four years later. On the other hand, relatives scored higher in the fear of one's own dying variable four years after the patient had been in ICU. Possibly, the lack of difference in three of the four variables (at the time of both interviews) could be explained by the fact that once the relatives had such a close and unexpected experience with death, fear of it did not disappear. In addition, as time passed, fear of an unexpected death, the prolonged latency of a terminal illness, physical degeneration and invalidity (fear of one's own dying) increased.

With reference to our investigation, the relatives evaluated had a close experience with the death process when the patient was in ICU. This might explain why, more than the fear of sudden death, with the passing of time, these relatives were more afraid of the dying process.

When a family member is admitted to ICU in an extremely critical state, between life and death, and with their quality of life severely deteriorated, their relatives are subjected to a great variety of factors capable of causing a strong emotional impact. These factors are related to the family's coping styles, the illness and treatment, and the relationship they have with the patient. With respect to coping styles, the most relevant elements could include the acceptance or denial of the patients' critical status, feelings of defenselessness and impotence since the patient now fully depends on equipment and hospital staff, and feelings of guilt regarding past experiences with the patient. Relatives might also feel that they did not do everything possible to avoid the patients' sudden admission to ICU and/or exhausted when the critical phase is extended over time. The second group of variables is related to the illness and its treatment. When relatives are notified of the diagnosis, prognosis and evolution of the illness, the well-being of the family is negatively affected. Also, information regarding treatment is given in a strange, unknown and invasive context, not common to the family environment. The third group of elements involves the relationship the relatives have with the patient. In most cases, hospital staff become the only link to the outside world.

We can also confirm that, frequently, if the patients' quality of life is poor due to his/her condition, relatives remain strongly involved in caring for the patient after his/her release from ICU. All of this could easily explain the enormous upset that, above all, the principle caregiver, experiences. This upset is expressed in excessive contemplation, a programmed routine, hysterical behavior, submission, withdrawal, repetitive behaviors, etc., and results in numerous physical and mental illnesses (Eisdofer, Kennedy, Wisnieski, \& Cohen, 1980).

We recognize, more and more, that the stress caused by caregiving can be distinct, but it doesn't necessarily mean that it worsens because an illness becomes chronic. Caregivers might adapt very successfully to facing the stress caused by a long term illness. That is, relatives might face the situation successfully over a long period of time due to having more experience as a caregiver (Townsend, Noelker, Deimling \& Bass, 1989).

In recent years, there has been a significant increase in the percentage of people who survive their stay in ICU thanks to medical advances and technology development. However, few investigations have been carried out regarding how patients evolve psychosocially after being released. Some authors report that patients who have been in an ICU do not experience changes in their physical activities or social status after their release. They say that, if there is a deterioration, it is minimal and does not influence the perception the patient has of their quality of life (Capuzzo et al., 1996; Zaren \& Hedstrand, 1987).

Still, other authors report that there is a decrease in the quality of life in these patients more than six months after being released from ICU, but that these deteriorations are due to other variables such as age, and the quality of life the patient had at the time s/he was admitted to the ICU (Vázquez, 1996; Vázquez, Rivera, et al., 1996). And so, some studies conclude that the quality of life of ICU patients suffers after being released when compared to subjects in the general population and when controlling age and sex. Also, patients who have been in ICU for a period of one to two years are more physically deteriorated and present with a greater level of depression and anxiety than the general populations (Vázquez, 1996; Vázquez et al., 1996). For example, Brooks et al., (1997) completed a study in which the results showed that one year after being released, the patients that had been in ICU had more health problems. They were more anxious and depressed, they had greater dependency on others, and their sexual activity level was decreased compared to the general population. Those who did not see themselves as completely healthy/recovered were less satisfied with their quality of life as compared to those who felt completely healthy/recovered and the general population. 
In short, the data regarding the psychosocial evolution of ICU patients are contradictory. More studies are needed to ascertain more conclusive results as well as to observe the affect on relatives.

In sum, some of these patients present with a poor quality of life as a result of the illness or injury for which they were admitted to the ICU. The patient is affected as well as his/her relatives, especially when the illness/injury becomes chronic and does not disappear with the passing of time (as in traumatic amputations, paraplegics, quadriplegics, etc.).

\section{References}

Affleck, G., Tennen, H., \& Rowe, J. (1990). Mothers, fathers, and the crisis of newborn intensive care. Infant Mental Health Journal, 1, 12-25.

Anguera, B. (1978). Aproximación psicológica al problema del lesionado medular traumático. [Psychological Aspects of the Traumatically Injured Spine.]. Anuario de Psicología, 19, 5-25.

American Psychiatric Association (1994). Diagnostic and statistical manual of mental disorders ( $4^{\text {th }}$ ed.). Barcelona: Masson.

Bennun, I. (1999). Intensive care units: A systemic perspective. Journal of Family Therapy, 1, 96-112.

Benoliel, J. (1985). Loss and terminal illness. Nursing Clinics of North America, 2, 439-448.

Breslau, N., Staruch, K.S., \& Mortimer, E.A. (1982). Psychological distress in mothers with disabled children. American Journal of Diseases of Children, 132, 682-686.

Brooks, R., Kerridge, R., Hillman, K, Bauman, A., \& Daffurn, K. (1997). Quality of life outcomes after intensive care. Intensive Care Medicine, 23, 581-586.

Broome, M.F. (1985). Working with the family of a critically ill child. Heart and Lung, 17, 682-688.

Capuzzo, M., Bianconi, M., Contu, P., Pavoni, V., \& Gritti, G. (1996). Survival and quality of life after intensive care. Intensive Care Medicine, 22, 947-953.

Dörr-Zegers, O. (1988). Espacio y tiempo en la unidad de cuidado intensivo. [Space and Time in the Intensive Care Unit.]. Actas Luso-Españolas de Neurología y Psiquiatría, 4, 246-254.

Eisdofer,C., Kennedy, G., Wisnieski, W., \& Cohen, D. (1980). Depression and attributional style in families coping with the stress of caring for a relative with Alzheimer's disease. Gerontologist, 20, 649-655.

Flórez, J.A. (2001). Aspectos psicoafectivos del enfermo terminal: Atención ética integral. [Psycho affective aspects of the terminally ill: Basic ethics.]. Barcelona: Astrazeneca.

Frías, R. (1994). El estrés en las UCI.[Stress in the ICU.]. Madrid: Universidad de Alcalá.

Fuller-Jonap, F., \& Haley, W.E. (1995). Mental and physical healthy of male caregivers of a spouse with Alzheimer's disease. Journal Aging Health, 7, 99-118.

Gafo, J., Vidal, M., Gil, E., Urraca, S., Higuera, G., Fernández, J.M., et al. (1984). La eutanasia y el derecho a morir con dignidad. [Euthanasia and the right to die with dignity.]. Madrid: Paulina.
Gómez, E., López, M.A.., \& Cirera, E. (1997). El paciente en cuidados intensivos. [The patient in intensive care.]. In J.E. Rojo \& E. Cirera (Eds.), Interconsulta psiquátrica (pp. 469477). Barcelona: Masson.

Holmes-Garret, C. (1990). The crisis of the forgotten family: A single session group in the ICU waiting room. Social Work with Groups, 4, 141-157.

Jay, S. (1977). Pediatric intensive care: Involving parents in the care of their child. Maternal-Child Nursing Journal, 8, 195-204.

Kendell, J.H., Slyter, H., \& Klaus, M.H. (1970).The mourning response of parents to the death of newborn infant. New England Journal of Medicine, 283, 344-349.

King, A.C., Oka, R.K., \& Young, D.R. (1994). Ambulatory blood pressure and heart rate responses to the stress of work and care giving in older women. Journal of Gerontology, 49, 239-245.

Krugg, S.S. (1987). Cuestionario de Análisis Clínico. [Clinical Analysis Questionairre.]. Madrid: TEA Ediciones, S.A.

Moos, R.H., Moos, B.S., \& Trickett, E.J. (1989). Escalas de Clima Social: Familia, Trabajo, Instituciones Penitenciarias, Centro Escolar. [Family Environment Scales: Family, Work, Penitentiary System, Schools.]. Madrid: TEA Ediciones, S.A.

Pérez, M.A. (2001). Apoyo psicológico en cuidados intensivos. [Psychological support in intensive care.]. In L.M. Torres (Ed.), Tratado de cuidados críticos y emergencias (Vol. 1, pp. 157170). Madrid: Arán Ediciones, S.L.

Pérez, M.A., \& Lozano, J.F. (1994). Intervención psicológica en medicina: Familiares de pacientes críticos y crónicos. [Psychological intervention in medicine: Relatives of critical and chronic patients.]. In M. Garrido \& J. García (Eds.), Psicoterapia: Modelos Contemporáneos y Aplicaciones (pp. 661-694). Valencia: Promolibro.

Pérez, M.A., Murillo, F., Dominguez, J.M., \& Nuñez, A. (1992). Personalidad, tipología familiar, nivel de religiosidad y actitudes hacia el cuerpo y la muerte en los familiares de pacientes ingresados en UCI. [Personality, family characteristics, religiousness and attitudes towards the body and death in relatives of ICU patients.]. Anales de Psiquiatría, 10, 405-410.

Rothstein, P. (1980). Psychological stress in families of children in a pediatric intensive care unit. Pediatric Clinics of North America, 27, 613-620.

Schulz, R., O’Brien, A.T., Bookwala, J., \& Fleissner, K. (1995). Psychiatric and physical morbidity effects of dementia care giving prevalence, correlates, and causes. Gerontologist, 25, 771-791.

Townsend, A., Noelker, L., Deimling, G., \& Bass, D. (1989). Longitudinal impact of interhousehold care giving on adult children's mental health. Psychological Aging, 29, 393-401.

Urraca, S. (1981). Actitudes ante la muerte (preocupación, ansiedad y temor) y religiosidad. [Attitudes regarding death (worry, anxiety and fear) and religiousness.] Unpublished Doctoral Thesis. Universidad Complutense, Madrid.

Vázquez, G. (1996). Calidad de vida. Un instrumento para medir la efectividad de los SMI. [Quality of life. An instrument for measuring SMI effectiveness.] Revista de Calidad Asistencial, $11,70-73$. 
Vázquez, G., Rivera, R., Pérez, A., González, A., Fernández, E., \& Navarrete, P. (1996). Analysis of quality of life in polytraumatized patients two years after discharge from an intensive care unit. The Journal of Trauma, 2, 326-332.

Vitaliano, P.P., Russo, J., \& Niaura, R. (1995). Plasma lipids and their relationships with psychosocial factors in older adults. Journals of Gerontology, 50, 18-24.
Zarén, M.D., \& Hedstrand, M.D. (1987). Quality of life among long-term survivors of intensive care. Critical Care Medicine, 8, 743-747.

Received: September 21, 2004 Revision Received: December 23, 2004 Accepted: January 10, 2005 